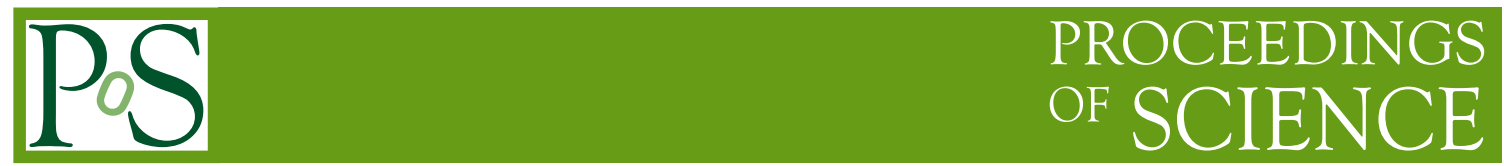

\title{
Indirect dark matter detection: recent results and perspectives
}

\section{Piero Ullio*}

Scuola Internazionale Superiore di Studi Avanzati

E-mail: ullioesissa.it

Frontiers of Fundamental Physics 14 - FFP14,

15-18 July 2014

Aix Marseille University (AMU) Saint-Charles Campus, Marseille

${ }^{*}$ Speaker. 